\title{
Effects of corticotropin-releasing factor on feeding and pancreatic polypeptide response in the $\mathrm{dog}$
}

\author{
M Okita, A Inui ${ }^{1}$, T Inoue, H Mizuuchi ${ }^{1}, \mathrm{~K}$ Banno $^{1}, \mathrm{~S} \mathrm{Baba}^{1}$ and \\ M Kasuga \\ Second Department of Internal Medicine, Kobe University School of Medicine, Kobe, Analytical Research Laboratory, Tanabe Seiyaku Co. Ltd \\ and ${ }^{1}$ Hyogo Medical Center for Adults, Akashi, Japan \\ (Requests for offprints should be addressed to A Inui, Second Department of Internal Medicine, Kobe University School of Medicine, Kusunoki-cho, Chuo-ku, \\ Kobe, 650 Japan)
}

\begin{abstract}
We have previously reported that corticotropin-releasing factor (CRF) is a potent stimulator of adrenocorticotropic hormone and cortisol secretion in the dog. Therefore, in the present study, we investigated the extrahypophysiotropic actions of CRF in this species. When CRF was injected into the third cerebral ventricle, it failed to inhibit food intake significantly at doses of $1.19,3.57$ and $11.9 \mathrm{nmol}$. This is in sharp contrast with the results in
\end{abstract}

rodents. At the 3.57 and $11.9 \mathrm{nmol}$ doses, CRF markedly stimulated the secretion of pancreatic polypeptide (PP), a hormone under vagal control, and at the highest dose CRF increased plasma glucose levels. These results suggest species differences in the feeding response to CRF and activation of the parasympathetic nervous system in the dog.

Journal of Endocrinology (1998) 156, 359-364

\section{Introduction}

Stress is well known to be accompanied by various physiological changes including activation of the pituitaryadrenal axis. This activation is dependent upon hypothalamic releasing hormones such as corticotropin-releasing factor (CRF) which regulate the secretion of adrenocorticotropic hormone (ACTH) from the pituitary. CRF is a 41-residue peptide characterized from ovine and rat hypothalami by Vale et al. (1981) and Spiess et al. (1983). CRF immunoreactivity (Swanson et al. 1983) and mRNA (Matthews et al. 1991) have been localized in the central nervous system in both the hypothalamus and extrahypothalamic structures. The CRF-containing cell bodies in the medial parvocellular division of the paraventricular nucleus, the fibers of which abundantly project into the neurohemal zone of the median eminence, are dominantly involved in the control of the pituitary-adrenal axis, which represents the primary role of CRF (Antoni 1986, Harbuz \& Lightman 1992). Within and outside the paraventricular nucleus, there are also CRF-containing perikarya, not involved in the pituitary function, which project into neuronal structures that modulate behavioral and autonomic functions (Swanson et al. 1983, Matthews et al. 1991, Petrusz \& Merchenthaler 1992).

In recent years, the effects of CRF on behavioral and autonomic functions have aroused as much interest as the role CRF plays in the secretion of ACTH and other pro- opiomelanocortin products (Gray 1993, Menzaghi et al. 1993, Richard 1993, Tache et al. 1993, Vamvakopoulos $\&$ Chrousos 1994). However, there are few data on the extrahypophysiotropic actions of CRF in species other than rodents. We and others have previously reported that $\mathrm{CRF}$ is a powerful stimulator of ACTH and cortisol secretion in the dog (Inoue et al. 1989, Reul et al. 1991). Therefore, in the present study, we examined the effects of CRF on food intake and on plasma pancreatic polypeptide (PP) secretion, an index of the activity of the parasympathetic nervous system (Schwartz 1983, Taylor 1989).

\section{Materials and Methods}

\section{Animals}

Normal adult mongrel dogs $(n=7)$, weighing approximately $12 \mathrm{~kg}$, were used in all the studies, which were carried out at least 3 days apart. They were housed in individual cages and kept under standard laboratory conditions (12 h light $/ 12 \mathrm{~h}$ darkness cycle; $22 \pm 2{ }^{\circ} \mathrm{C} ; 200 \mathrm{~g}$ dog food (Nissin Pet Food Co., Tokyo, Japan) daily), with tap water available ad libitum. After an overnight fast, animals were placed in jackets and allowed to remain in a fully conscious relaxed state during the experiments. All experiments were approved by our university animal care committee. 


\section{Surgical procedure}

Under sodium thiamylal anesthesia, 20-gauge stainless steel cannulas were permanently implanted toward, but not entering, the third cerebral ventricle of dogs, using dental cement. The methods used have been described previously (Inui et al. 1987, 1988, 1989, 1991). Experiments were conducted 2 weeks after implantation of the cannula in the brain ventricle.

On the day of the experiment, an i.v. butterfly needle(s) was placed in the superficial vein of the forelimb for blood sampling. The i.c.v. injection insert (a 24-gauge stainless steel tube) was attached by tubing to a syringe, placed in the cannula, and adjusted so that the tip was in the ventricle. The patency of the ventricular cannula was usually ascertained by observing the reflux of the cerebrospinal fluid. If we could not verify that peptides were injected into the ventricle, we omitted the data from the statistical analysis. The experimental design was a randomized block, and the saline test was run for each of the experiments. Ovine CRF (Peptide Institute, Osaka, Japan) was dissolved in saline vehicle and $100 \mu \mathrm{l}$ of the solution was injected into the third ventricle (i.c.v.) over $5 \mathrm{~min}$. Experiments were performed under $16 \mathrm{~h}$ fasting conditions.

\section{Experimental design}

Plasma glucose and PP secretion Seven dogs received i.c.v. injection of CRF $(1.19,3.57$ and $11.9 \mathrm{nmol})$ or saline vehicle as a control. Blood samples were obtained during the basal period and between 0 and 120 min after the injection of CRF. Results were expressed as the mean \pm s.E.M. The incremental integrated responses of PP and glucose were calculated in individual subjects, utilizing the trapezoidal method. The incremental integrated response is the incremental area under the curve after basal subtraction.

Food and water intakes Food was removed $16 \mathrm{~h}$ before the experiment (1700-0900 h), while water remained available ad libitum. CRF $(1.19,3.57$ and $11.9 \mathrm{nmol})$ or saline vehicle was injected i.c.v. into the seven dogs. The dogs were then given a premeasured quantity of a test meal, a highly palatable dog food (Delicious Cut: Sunrise Co., Osaka, Japan: protein 15\%, fat 23\%, carbohydrate $62 \%$ ) and water. Food and water intakes were recorded at $10 \mathrm{~min}$ intervals for $2 \mathrm{~h}$ after the injection. Results were expressed as $\mathrm{g}$ of food and $\mathrm{ml}$ of water ingested after i.c.v. CRF or saline administration, and cumulated at 10, 30, 60 and $120 \mathrm{~min}$.

Pretreatment with atropine Previously we found that a $20 \mu \mathrm{g}$ i.c.v. dose of atropine markedly inhibited PP response to i.c.v. cholecystokinin octapeptide (CCK-8) without producing gross behavioral changes or inhibition of food intake (Inui et al. 1988). Therefore we administered atropine $(20 \mu \mathrm{g} / 50 \mu \mathrm{l}$ saline per $2.5 \mathrm{~min})$ or saline vehicle into the third ventricle of seven dogs just before i.c.v. CRF $(3.57 \mathrm{nmol} / 50 \mu \mathrm{l}$ saline per $2.5 \mathrm{~min})$ and examined its effect on CRF-induced inhibition of food intake and release of PP. To rule out possible leakage of atropine into the peripheral circulation, we measured plasma atropine concentrations before, 60 and $120 \mathrm{~min}$ after $100 \mu \mathrm{g}$ atropine injection into the third ventricle. The sampling points were chosen based on the data that i.c.v. administered substances such as proglumide and PP do not appear acutely in the dog (Inui et al. 1987) and that the half-life of atropine is $4.125 \mathrm{~h}$ in the peripheral circulation (Adams et al. 1982).

Sample determinations Blood samples were collected in chilled tubes containing 400 kallikrein inhibitor units of aprotinin (Trasylol; Bayer AG, Leverkusen, Germany) and $1.2 \mathrm{mg}$ EDTA $/ \mathrm{ml}$ blood and centrifuged. The plasma was then frozen at $-20{ }^{\circ} \mathrm{C}$ until assayed. PP was measured by RIA, using a modification of the double-antibody technique (Inui et al. 1985, 1993), in which first the antibody was incubated with the sample for $48 \mathrm{~h}$ before the addition of iodinated PP to increase the sensitivity of the assay. Plasma glucose was determined by the glucose oxidase method. Plasma atropine concentrations were measured by HPLC after ether extraction with the minimum detection limit of $1 \mathrm{ng} / \mathrm{ml}$ (coefficient of variation $8 \cdot 0 \%$ ).

\section{Statistical methods}

Data were evaluated by ANOVA, followed by Dunnett's test. A level of $P<0.05$ was taken as statistically significant.

\section{Results}

Effects of i.c.v. CRF on food intake

Previously we found that i.c.v. CRF at a dose of $1.19 \mathrm{nmol}$ powerfully stimulated ACTH and cortisol secretion in the dog, the latter being nearly equivalent to that produced by insulin-induced hypoglycemia (Inoue et al. 1989). At this i.c.v. dose, CRF failed to inhibit food intake significantly (Fig. 1). The actual (cumulative) amount of food eaten at $10,30,60$ and $120 \mathrm{~min}$ was $318 \cdot 1 \pm 51 \cdot 8,328 \cdot 0 \pm$ $46 \cdot 3,335 \cdot 6 \pm 31 \cdot 1$ and $380 \cdot 0 \pm 81 \cdot 0 \mathrm{~g}$ after control saline injection, $291 \cdot 4 \pm 51 \cdot 0,304 \cdot 0 \pm 49 \cdot 5,387 \cdot 1 \pm 86 \cdot 0$ and $431.9 \pm 85.4 \mathrm{~g}$ after $1.19 \mathrm{nmol}$ CRF, $280.9 \pm 71.5$, $280 \cdot 9 \pm 71 \cdot 5, \quad 318 \cdot 6 \pm 77 \cdot 0$ and $360 \cdot 6 \pm 89 \cdot 2 \mathrm{~g}$ after $3 \cdot 57 \mathrm{nmol} \mathrm{CRF}$, and $249 \cdot 0 \pm 37 \cdot 7,269 \cdot 0 \pm 33 \cdot 1,310 \cdot 3 \pm$ $38 \cdot 2$ and $426 \cdot 5 \pm 50 \cdot 1 \mathrm{~g}$ after $11 \cdot 9 \mathrm{nmol}$ CRF injection. Thus dogs had almost finished eating within the first $10 \mathrm{~min}$ as reported previously (Inui et al. 1987, 1988, 1989, Sakatani et al. 1987), and the highest dose of CRF decreased food intake to $80 \%$ of control saline injection 

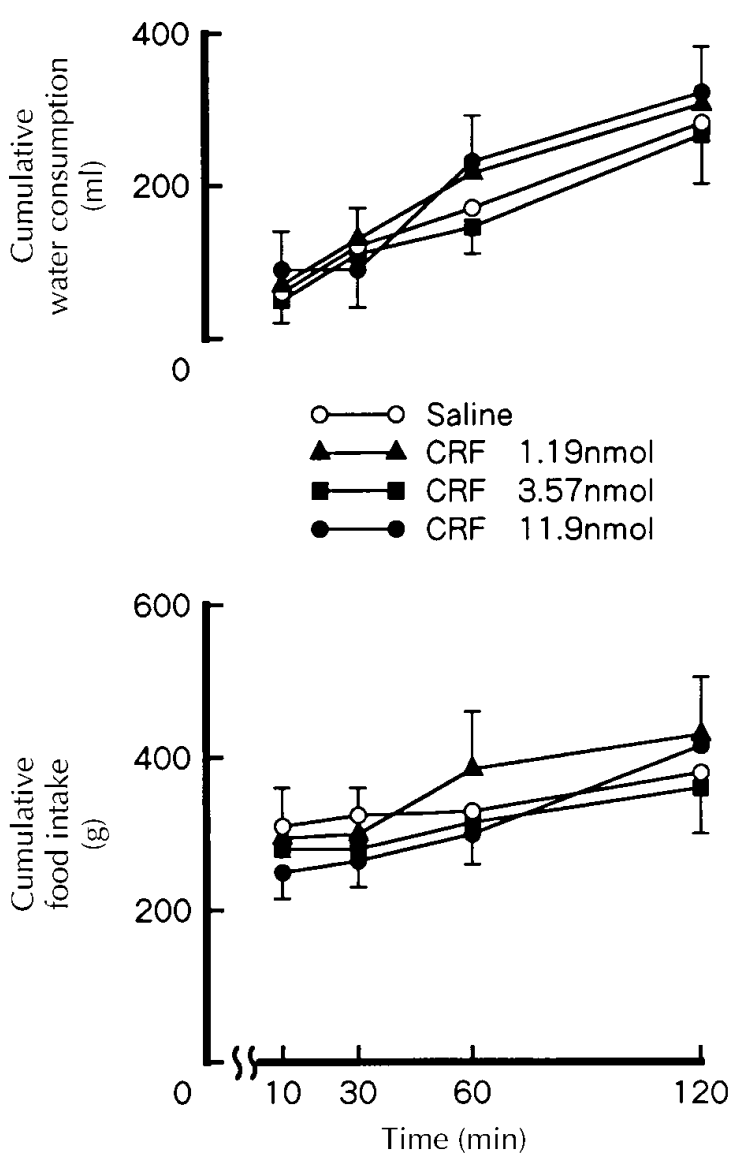

Figure 1 Effect of CRF injected into the third cerebral ventricle of seven dogs on food intake and water consumption. Results are expressed as amount of food or water ingested after i.c.v. injections.

although it did not reach statistical significance. This is quite different from the results of other feeding-inhibitory peptides such as CCK, which powerfully inhibited feeding in dogs (Inui et al. 1987, 1988, 1989, Sakatani et al. 1987). The cumulative food intake after injection of $1.19 \mathrm{nmol}$ CCK-8 was $149 \cdot 1 \pm 39 \cdot 4,194 \cdot 9 \pm 47 \cdot 6,239 \cdot 1 \pm 46 \cdot 9$ and $297 \cdot 7 \pm 62 \cdot 6 \mathrm{~g}$ at $10,30,60$ and 120 min respectively in this study. CRF did not decrease water consumption (Fig. 1). We found no gross behavioral changes such as vomiting when CRF was injected into the ventricle.

\section{Effects of i.c.v. CRF on autonomic responses}

CRF at a dose of $1.19 \mathrm{nmol}$ failed to alter plasma glucose and $\mathrm{PP}$ responses significantly (Figs 2 and 3 ). However, at the dose of $3.57 \mathrm{nmol}$, CRF significantly stimulated PP secretion, and at the highest dose $(11.9 \mathrm{nmol})$ it markedly increased plasma PP concentrations over the entire $2 \mathrm{~h}$ observation period. Plasma glucose was increased only at the highest dose of CRF.

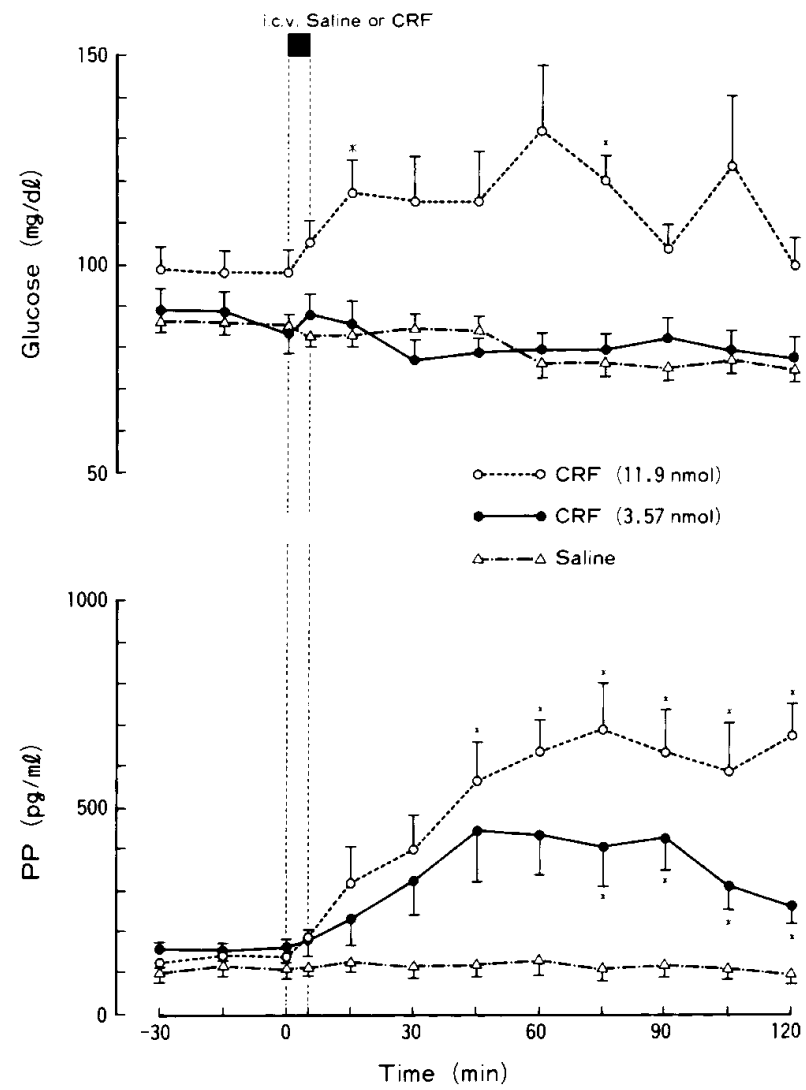

Figure 2 Effect of CRF injected into the third cerebral ventricle of seven dogs on plasma glucose and PP levels. ${ }^{*} P<0 \cdot 05$ or less vs basal.

Effects of i.c.v. pretreatment with atropine

Atropine administered i.c.v. at a dose $(20 \mu \mathrm{g})$ that did not affect food intake (Inui et al. 1988) significantly reduced the $\mathrm{PP}$ response to the peptide (integrated $\mathrm{PP}$ response: $9 \cdot 6 \pm 6 \cdot 4$ vs $22 \cdot 2 \pm 6 \cdot 8 \mathrm{ng} / \mathrm{min}$ per $\mathrm{ml}$ (control); $P<0 \cdot 05$ ). The plasma atropine concentrations remained below the detection limit $(1 \mathrm{ng} / \mathrm{ml})$ after injection of $100 \mu \mathrm{g}$ atropine, a dose that was five times higher than that used in the study, into the third ventricle $(n=5)$.

\section{Discussion}

Major advances in the study of CRF on stress responses have been made through almost exclusive use of laboratory rodents. Little information is available for other mammalian species, although Brown and associates performed a variety of studies in dogs examining the actions of i.c.v. $\mathrm{CRF}$ on plasma levels of catecholamines and glucose as well as on cardiovascular and hemodynamic function (Brown \& Fisher 1983, Lenz et al. 1986). In the present study, we examined the effects of CRF on behavioral and 

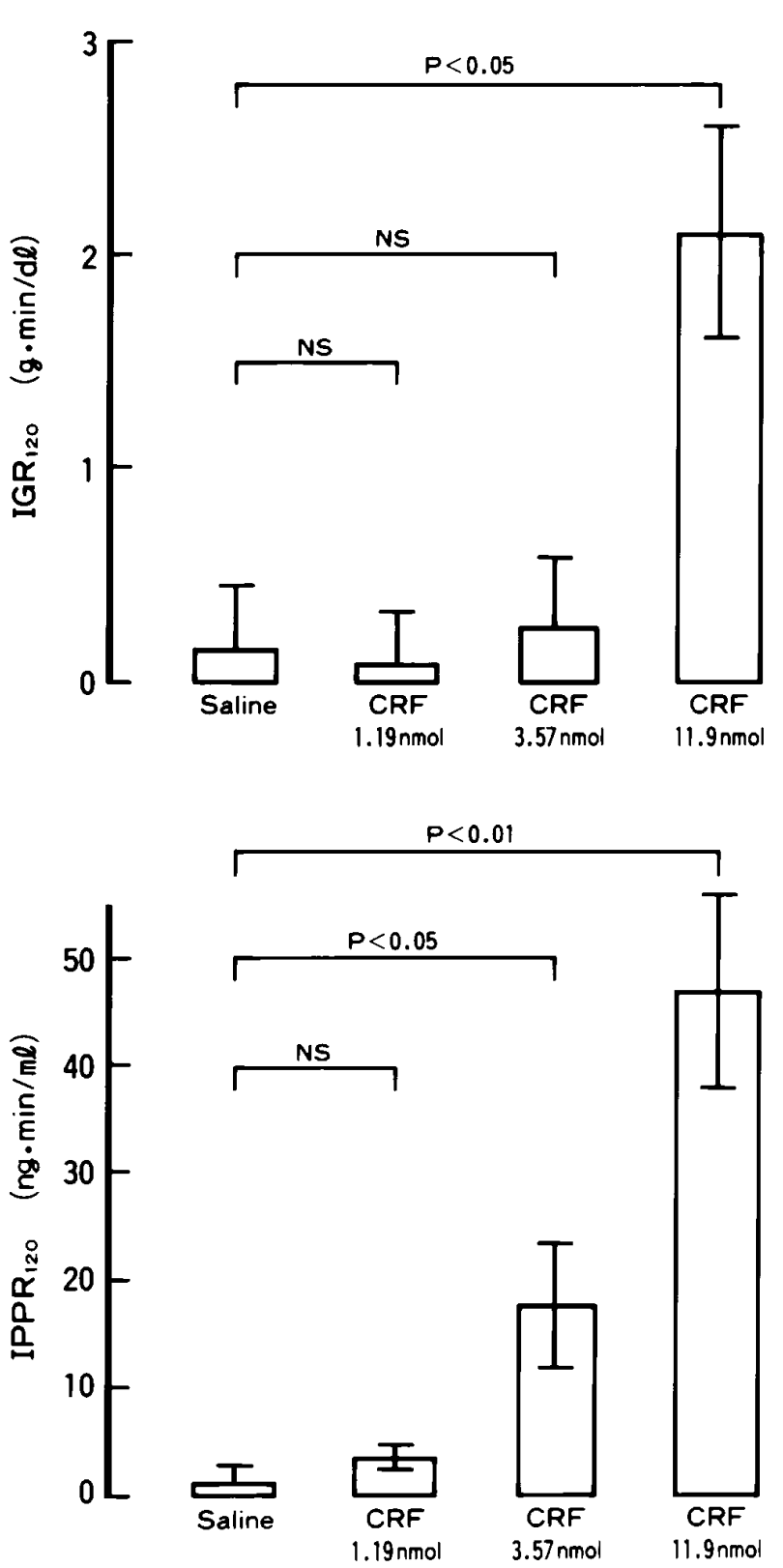

Figure 3 Effect of CRF injected into the third cerebral ventricle of seven dogs on integrated plasma glucose $\left(\mathrm{IGR}_{120}\right)$ and PP $\left(\mathrm{IPPR}_{120}\right)$ responses.

autonomic functions in the dog. We found that CRF injected into the third cerebral ventricle failed to inhibit food intake significantly up to a dose $(11.9 \mathrm{nmol})$ at least ten times higher than that stimulating cortisol secretion (Inoue et al. 1989). Thus the inhibitory effect of CRF on food intake was much less potent than other feedinginhibitory peptides, such as CCK, which powerfully inhibited the initiation of feeding under the same fasting conditions (Inui et al. 1987, 1988, 1989). Since CRF is a major feeding-inhibitory peptide in the hypothalamus of rodents (Britton et al. 1982, Morley \& Levine 1982, Morley 1987, Richard 1993), the present findings indicate species differences in the feeding response to exogenous CRF.

Although we used ovine CRF instead of canine CRF which is not yet characterized, the possible species difference in CRF structure rather than CRF action is a less likely explanation in view of the potent actions of ovine CRF on various physiological functions of dogs (Brown \& Fisher 1983, Lenz et al. 1986, Inoue et al. 1989, Reul et al. 1991, the present study). Urocortin, a CRF-related peptide, was recently discovered in mammalian brain and found to have potent appetite-suppressing effects (Vaughan et al. 1995, Spina et al. 1996). It is thus to be determined whether urocortin is an endogenous CRF-like peptide in this species that is responsible for the inhibitory effects on appetite, as was demonstrated for rodents (Spina et al. 1996).

We also found in this study that CRF potently stimulated the secretion of PP, a hormone under vagal control (Schwartz 1983, Taylor 1989), in a dose-dependent manner in the dog. This action of CRF was observed at lower doses than those that caused an increase in plasma glucose. This immediate elevation of plasma glucose levels suggests that there is early activation of the sympathetic nervous system leading to glucagon secretion and/or glycogenolysis (but not inhibition of insulin secretion (M Okita, A Inui, T Inoue, H Mizuuchi, K Banno, S Baba \& M Kasuga, unpublished observations)) and therefore resulting in elevated glucose levels. At the highest dose used, CRF increased plasma PP concentrations to almost the levels observed after two potent stimuli of PP secretion, i.e. ingestion of a meal and insulin-induced hypoglycemia (Inui et al. 1993). It was demonstrated that PP, released into the circulation, traverses the blood/brain barrier through leaky regions of this barrier in the area postrema, binds to the specific reseptors, and directly regulates vagal input to the stomach and other gastrointestinal organs (Whitcomb et al. 1990, McTigue et al. 1993). The resulting enhancement of gastric motility and acid secretion (McTigue et al. 1993) may contribute in part to the accelerated gastric emptying and acid secretion observed during hypoglycemia, because CRF is well known to be activated by hypoglycemic stress (Petrusz \& Merchenthaler 1992, Gray 1993, Menzaghi 1993).

Recent studies suggest that neuropeptides such as thyrotropin-releasing hormone specifically activate vagal efferent neurons in the dorsal motor nucleus (McTigue \& Rogers 1992). Thyrotropin-releasing hormone administered to the ventricle also stimulates PP secretion in the $\operatorname{dog}$ (M Okita, A Inui, T Inoue, H Mizuuchi, K Banno, S Baba \& M Kasuga, unpublished observations). Although the site of action of CRF in the brain is not apparent at this stage, CRF-induced PP secretion was suppressed by i.c.v. pretreatment with atropine which acted without 
appearing in the peripheral circulation. Therefore CRF would affect the muscarinic cholinergic system near the ventricular structure to release PP (Ban 1966), as demonstrated for CCK in this species (Inui et al. 1988). The dose of atropine used in this study is well within the range $(1-100 \mu \mathrm{g})$ in which atropine administered locally to the brain or i.c.v. affects behavioral functions such as appetite (Ikemoto \& Panksepp 1996), locomotion (Brudzynski et al. 1991) and grooming (Torre \& Celis 1989) in rats, and aggression (Dawra et al. 1988) in cats. These results suggest physiological relevance of the dose of atropine and central cholinergic systems in PP secretion. However, the efferent mechanism of CRF-induced PP release is not yet established. The latency between CRF injection and statistically significant changes in plasma PP levels may suggest that it is a consequence of peripheral changes secondarily produced by central CRF injection. Although this possibility could not be ruled out, peripherally administered CRF was also reported to produce slow PP response in contrast with immediate stimulation of cortisol secretion (Lytras et al. 1984). Therefore a more likely explanation may be that activation of sympathetic outflow results in alleviation of PP secretion simultaneously evoked by vagal stimulation.

In conclusion, we found that $\mathrm{CRF}$ is a weak inhibitor of feeding but a potent stimulator of PP secretion in the dog. This suggests species differences in the feeding response to CRF, as demonstrated for other peptides such as CCK (Della-Fera \& Baile 1979, Morley et al. 1985, Inui et al. 1993) and neuropeptide Y (Inui et al. 1991, Sipols et al. 1996), and activation of the parasympathetic nervous system in this species.

\section{Acknowledgements}

This work was supported in part by Grants-in-Aid for Scientific Research (C) 06671 O33 and for Developmental Scientific Research (B) 06557060 from the Ministry of Education, Science, and Culture of Japan (to A I).

\section{References}

Adams RG, Verma P, Jackson AJ \& Miller RL 1982 Plasma pharmacokinetics of intravenously administered atropine in normal human subjects. Journal of Clinical Pharmacology 22 477-481.

Antoni FA 1986 Hypothalamic control of adrenocorticotropin secretion: advances since the discovery of 41-residue corticotropinreleasing factor. Endocrine Reviews 7 351-378.

Ban T 1966 The septo-preoptico-hypothalamic system and its autonomic function. Progress in Brain Research 21 1-43.

Britton D, Koob G, River J \& Vale W 1982 Intraventricular corticotropin-releasing factor enhances behavioral effects of novelty. Life Sciences 31 363-367.

Brown MR \& Fisher LA 1983 Central nervous system effects of corticotropin releasing factor in the dog. Brain Research 280 75-79.

Brudzynski SM, McLachlan RS \& Girvin JP 1991 Involvement of M1 and M2 muscarinic receptors of the basal forebrain in cholinergically mediated changes in rat locomotion. Progress in NeuroPsychopharmacology and Biological Psychiatry 15 279-284.

Dawra PS, Aneja IS, Manchanda SK, Bhatia SC \& Tandon OP 1988 Midbrain cholinergic mechanisms in elicitation of hypothalamic aggressive responses in cats. Progress in Neuro-Psychopharmacology and Biological Psychiatry 12 445-453.

Della-Fera MA \& Baile CA 1979 Cholecystokinin octapeptide: continuous picomole injections into the cerebral ventricles of sheep suppress feeding. Science 206 471-473.

Gray TS 1993 Amygdaloid CRF pathways. Role in autonomic, neuroendocrine, and behavioral responses to stress. Annals of New York Academy of Sciences 697 53-60.

Harbuz MS \& Lightman SL 1992 Review: stress and the hypothalamo-pituitary-adrenal axis: acute, chronic and immunological activation. Journal of Endocrinology 134 327-339.

Ikemoto S \& Panksepp J 1996 Dissociations between appetitive and consummatory responses by pharmacological manipulations of reward-relevant brain regions. Behavioral Neuroscience 110 331-345.

Inoue $\mathrm{T}$, Inui A, Okita M, Sakatani N, Oya M, Morioka H, Mizuno N, Oimomi M \& Baba S 1989 Effect of neuropeptide Y on the hypothalamic-pituitary-adrenal axis in the dog. Life Sciences $\mathbf{4 4}$ 1043-1051.

Inui A, Mizuno N, Oya M, Suenaga K, Morioka H, Ogawa T, Ishida M \& Baba S 1985 Cross-reactivities of neuropeptide Y and peptide $\mathrm{YY}$ with pancreatic polypeptide antisera: evidence for the existence of pancreatic polypeptide in the brain. Brain Research 330 386-389.

Inui A, Inoue T, Sakatani N, Oya M, Morioka H \& Baba S 1987 Proglumide has access to brain and antagonizes the central satiety effect of cholecystokinin octapeptide in the dog. Brain Research 417 355-359.

Inui A, Inoue T, Sakatani N, Oya M, Morioka H, Ogawa T, Mizuno N \& Baba S 1988 Mechanism of actions of cholecystokinin octapeptide on food intake and insulin and pancreatic polypeptide release in the dog. Peptides 9 1093-1100.

Inui $\mathrm{A}$, Okita $\mathrm{M}$, Inoue $\mathrm{T}$, Sakatani $\mathrm{N}$, Oya $\mathrm{M}$, Morioka $\mathrm{H}$, Oimomi M \& Baba S 1989 Effect of cholecystokinin octapeptide analogues on food intake in the dog. American Journal of Physiology 257 R746-R751.

Inui A, Okita M, Nakajima M, Inoue T, Sakatani N, Oya M, Morioka H, Okimura Y, Chihara K \& Baba S 1991 Neuropeptide regulation of feeding in dogs. American Journal of Physiology 261 R588-R594.

Inui A, Okita M, Miura M, Hirosue Y, Mizuno N, Baba S \& Kasuga M 1993 Plasma and cerebrospinal fluid levels of pancreatic polypeptide in the dog: effects of feeding, insulin-induced hypoglycemia, and physical exercise. Endocrinology 132 1235-1239.

Lenz HJ, Klapdor R, Hester SE, Webb VJ, Galyean RF, Rivier JE \& Brown MR 1986 Inhibition of gastric acid secretion by brain peptides in the dog. Role of the autonomic nervous system and gastrin. Gastroenterology 91 905-912.

Lytras N, Grossman A, Rees LH, Schally AV, Bloom SR \& Besser GM 1984 Corticotropin releasing factor: effects on circulating gut and pancreatic peptides in man. Clinical Endocrinology 20 725-729.

McTigue DM \& Rogers RC 1992 Thyrotropin releasing hormone: a putative central neurotransmitter regulating digestive function. In Advances in the Innervation of the Gastrointestinal Tract. Ed G Holle. Amsterdam: Excerpta Medica.

McTigue DM, Edwards NK \& Rogers RC 1993 Pancreatic polypeptide in dorsal vagal complex stimulates gastric acid secretion and motility in rats. American Journal of Physiology 265 G1169-G1176.

Matthews SG, Heavens RP \& Sirinathsinghji DJ 1991 Cellular localization of corticotropin-releasing factor mRNA in the ovine brain. Molecular Brain Research 11 171-176.

Menzaghi F, Heinrichs SC, Pich EM, Weiss F \& Koob GF 1993 The role of limbic and hypothalamic corticotropin-releasing factor in behavioral responses to stress. Annals of New York Academy of Sciences 697 142-154. 
Morley JE 1987 Neuropeptide regulation of appetite and weight. Endocrine Reviews 8 256-287.

Morley JE \& Levine AS 1982 Corticotropin-releasing factor, grooming and ingestive behaviors. Life Sciences 31 1459-1464.

Morley JE, Levine AS, Bartness TJ, Nizielski SE, Shaw MJ \& Hughes JJ 1985 Species differences in the response to cholecystokinin. Annals of New York Academy of Sciences 448 413-417.

Petrusz P \& Merchenthaler I 1992 The corticotropin-releasing factor system. In Neuroendocrinology, pp 129-183. Ed CB Numeroff. Boca Raton: CRC Press.

Reul JMHM, Rothuizen J \& deKloet ER 1991 Age-related changes in the dog hypothalamic-pituitary-adrenocortical system: neuroendocrine activity and corticosteroid receptors. Journal of Steroid Biochemics and Molecular Biology 40 63-69.

Richard D 1993 Involvement of corticotropin-releasing factor in the control of food intake and energy expenditure. Annals of New York Academy of Sciences 697 155-172.

Sakatani N, Inui A, Inoue T, Oya M, Morioka H \& Baba S 1987 The role of cholecystokinin octapeptide in the central control of food intake in the dog. Peptides 8 651-656.

Schwartz TW 1983 Pancreatic polypeptide: a hormone under vagal control. Gastroenterology 85 1411-1425.

Sipols AJ, Figlewicz DP, Seeley RJ, Chavez M, Woods SC \& Porte Jr D 1996 Intraventricular neuropeptide $\mathrm{Y}$ does not stimulate food intake in the baboon. Physiology Behaviour 60 717-719.

Spiess J, River J \& Vale W 1983 Sequence of rat hypothalamic corticotropin-releasing factor with the $o$-phthaladehyde strategy. Biochemistry 22 4341-4346.

Spina M, Merlo-Pich E, Chan RKW, Basso AM, Rivier J, Vale W \& Koob GF 1996 Appetite-suppressing effects of urocortin, a CRFreleated neuropeptide. Science 273 1561-1564.

Swanson LW, Sawchenko PE, Rivier J \& Vale W 1983 The organization of ovine corticotropin-releasing factor (CRF) immunoreactive cells and fibers in the rat brain: an immunohistochemical study. Neuroendocrinology 36 165-186.

Tache Y, Monnikes H, Bonaz B \& Rivier J 1993 Role of CRF in stress-related alterations of gastric and colonic motor function. Annals of New York Academy of Sciences 697 233-243.

Taylor IL 1989 Pancreatic polypeptide family: pancreatic polypeptide, neuropeptide Y, and peptide YY. In Handbook of Physiology, section 6, vol 2, pp 475-543. Eds BB Rauner, GM Makhlouf \& SG Schultz. Bethesda: American Physiological Society.

Torre E \& Celis ME 1989 a-Melanotropin induced excessive grooming involves brain acetylcholine: possible interaction in the vental tegmental area. Acta Physiologica Pharmacologica Latinoamericana 39 49-56.

Vale W, Spiess J, Rivier C \& Rivier J 1981 Characterization of a 41-residue ovine hypothalamic peptide that stimulates secretion of corticotropin and beta-endorphin. Science 213 1394-1397.

Vamvakopoulos NC \& Chrousos GP 1994 Hormonal regulation of human corticotropin-releasing hormone gene expression: implications for the stress response and immune/inflammatory reaction. Endocrine Review 15 409-420.

Vaughan J, Donaldson C, Bittencourt J, Perrin MH, Lewis K, Sutton S, Chan R, Turnbull AV, Lovejoy D, Rivier C, Rivier J, Sawchenko PE \& Vale W 1995 Urocortin, a mammalian neuropeptide related to fish urocortin I and to corticotropinreleasing factor. Nature 378 287-292.

Whitcomb DC, Taylor IL \& Vigna SR 1990 Characterization of saturable binding sites for circulating pancreatic polypeptide in rat brain. American Journal of Physiology 259 G687-G691.

Received 27 March 1997

Revised manuscript received 21 July 1997 Accepted 9 September 1997 